\title{
GSH levels affect weight loss in individuals with metabolic syndrome and obesity following dietary therapy
}

\author{
NIKOLAOS GOUTZOURELAS ${ }^{1,2}$, MARINA ORFANOU ${ }^{2}$, IOANNIS CHARIZANIS ${ }^{3}$, \\ GEORGE LEON $^{2}$, DEMETRIOS A. SPANDIDOS ${ }^{4}$ and DEMETRIOS KOURETAS ${ }^{1}$ \\ ${ }^{1}$ Department of Biochemistry and Biotechnology, University of Thessaly, 41500 Larissa; \\ ${ }^{2}$ Eatwalk IKE, 15124 Athens; ${ }^{3}$ Obesity Medical Centre, 55133 Thessaloniki; \\ ${ }^{4}$ Laboratory of Clinical Virology, University of Crete, Medical School, 71409 Heraklion, Greece
}

Received March 15, 2018; Accepted May 10, 2018

DOI: 10.3892/etm.2018.6204

\begin{abstract}
This study examined the effects of redox status markers on metabolic syndrome (MetS) and obesity before and after dietary intervention and exercise for weight loss. A total of 103 adults suffering from MetS and obesity participated in this study and followed a personalized diet plan for 6 months. Body weight, body fat $(\mathrm{BF})$ percentage $(\mathrm{BF} \%)$, respiratory quotient (RQ) and the redox status markers, reduced glutathione (GSH), thiobarbituric acid reactive substances (TBARS) and protein carbonyls (CARB), were measured twice in each individual, before and after intervention. Dietary intervention resulted in weight loss, a reduction in $\mathrm{BF} \%$ and a decrease in $\mathrm{RQ}$. The GSH levels were significantly decreased following intervention, while the levels of TBARS and CARB were not affected. Based on the initial GSH levels, the patients were divided into 2 groups as follows: The high GSH group (GSH, $>3.5 \mu \mathrm{mol} / \mathrm{g}$ $\mathrm{Hb}$ ) and the low GSH group (GSH $<3.5 \mu \mathrm{mol} / \mathrm{g} \mathrm{Hb}$ ). Greater weight and BF loss were observed in patients with high GSH levels. It was observed that patients with MetS and obesity with high GSH values responded better to the dietary therapy, exhibiting more significant changes in weight and $\mathrm{BF} \%$. This finding underscores the importance of identifying redox status markers, particularly GSH, in obese patients with MetS. Knowing the levels of GSH may aid in developing a better design of an individualized dietary plan for individuals who wish to lose weight.
\end{abstract}

Correspondence to: Professor Demetrios Kouretas, Department of Biochemistry and Biotechnology, University of Thessaly, Viopolis, 41500 Larissa, Greece

E-mail:dkouret@uth.gr

Abbreviations: EDTA, ethylenediaminetetraacetic acid; GSH, glutathione; ROS, reactive oxygen species; TBA, thiobarbituric acid; TBARS, thiobarbituric acid reactive substances; TCA, trichloroacetic acid; DNPH, 2,4-dinitrophenylhydrazine

Key words: metabolic syndrome, obesity, oxidative stress, glutathione, weight loss

\section{Introduction}

In modern western societies, an increasing number of the population are confronted with a diagnosis of metabolic syndrome (MetS). Specifically, approximately 24\% of the European population and $34 \%$ of the American population suffer from MetS $(1,2)$. MetS is a cluster of at least three of the following medical conditions: Abdominal (central) obesity, elevated blood pressure, elevated fasting plasma glucose levels, high serum triglyceride levels and low high-density lipoprotein (HDL) levels. MetS is associated with the risk of developing cardiovascular disease and diabetes type $2(3,4)$. MetS usually occurs due to excessive food intake with high energy density, the lack of physical exercise and genetic predisposition. Diet and physical exercise are the basis for dealing with obesity. Food quality can be improved by reducing energy consumption, which is achieved by decreasing the consumption of high-energy foods, such as those with a high fat and sugar content, and by increasing fiber intake (5-7).

Free radicals are produced during normal metabolism and are involved in normal cellular functions, such as cell signaling, gene expression and apoptosis $(8,9)$. Apart from endogenous sources of free radicals, there are also exogenous sources. The main exogenous sources of free radicals are smoking, exposure to air pollution, ultraviolet light and ionizing radiation, and poor food quality (10). The major free radicals include the reactive forms of oxygen species (ROS), such as superoxide anion radical $(\mathrm{O} 2 \bullet-)$, hydroxyl radical $(\mathrm{OH} \bullet)$ and peroxyl radical (RO2•), as well as reactive nitrogen species (RNS), such as nitric oxide and the peroxynitrite radical (ONOO•). The overproduction of free radicals due to their high reactivity can lead to oxidative damage to macromolecules, such as lipids, proteins and DNA by affecting their functionality.

However, living organisms have a defense system against free radicals consisting of enzymes and low molecular weight molecules in order to maintain a balance between free radical production and antioxidant mechanisms. The major antioxidant enzymes are catalase (CAT), glutathione peroxidase (GPx), superoxide dismutase (SOD) and paraoxonase 1 (PON1). Low molecular weight antioxidants include molecules, such as glutathione (GSH), vitamins $\mathrm{C}$ and $\mathrm{E}$, uric acid and ubiquinone $(8,11)$. When this equilibrium is disrupted either due 
to overproduction of free radicals or due to the reduction of antioxidant mechanisms, oxidative stress occurs (12).

The past decade has brought forth significant interest towards the research of free radicals in obesity, diabetes and MetS. Studies have demonstrated that fat accumulation and insulin resistance in patients with MetS is associated with increased oxidative stress, suggesting that oxidative stress plays a critical role in the progression of the disease $(13,14,17)$. MetS can lead to the onset of type 2 diabetes, which is characterized by elevated blood glucose levels due to increased insulin resistance. Several studies have demonstrated that symptoms of MetS and diabetes, such as hyperglycemia, insulin resistance and hyperlipidemia are responsible for increased levels of oxidative stress through various mechanisms. Some of these include elevated glycosylation products (AGEs), increased inflammation and the increased production of peroxides in the mitochondria (13-17).

A recent study by our research team analysed the levels of redox status markers in people diagnosed with MetS (18). The results revealed that the levels of oxidative stress fluctuated among patients. However, two classes of patients were distinguished from the levels of a basic cellular antioxidant, GSH. This sutdy aimed to investigate changes in weight, body fat percentage $(\mathrm{BF} \%)$, respiratory quotient $(\mathrm{RQ})$ and a series of redox status markers in patients suffering from MetS following a 6-month follow-up and dietary therapy.

\section{Materials and methods}

Individuals. A total of 103 adult subjects suffering both MetS and obesity participated in the present study. Of these, 73 were women and 30 were men. The age of the study subjects was $42.01 \pm 1.11$ [mean \pm standard error of the mean (SEM)]. All experimental procedures were performed in accordance with the European Union Guidelines laid down in the 1964 Declaration of Helsinki and were approved by the Institutional Review Board of the University of Thessaly (Larissa, Greece).

Blood collection and handling. The participants visited the Standard Centre of Bioassays, 'Omiostasis' in Athens (Greece) twice and blood samples were collected at the beginning and after dietary intervention, 6 months later. Blood samples were drawn from a forearm vein of seated individuals and stored in ethylenediaminetetraacetic acid (EDTA; Becton-Dickinson, Franklin Lakes, NJ, USA) tubes for measuring the levels of thiobarbituric acid reactive substances (TBARS), protein carbonyls (CARB) protein carbonyls (CARB) and GSH. The samples were then centrifuged immediately at $1,370 \mathrm{x} \mathrm{g}$ for $10 \mathrm{~min}$ at $4^{\circ} \mathrm{C}$ and erythrocytes were divided from the plasma. The erythrocytes were lysed with distilled water $(1: 1 \mathrm{v} / \mathrm{v})$, inverted and centrifuged at $4,020 \mathrm{x} \mathrm{g}$ for $15 \mathrm{~min}$ at $4^{\circ} \mathrm{C}$, and the erythrocyte lysate was then collected. A small amount of erythrocyte lysate $(500 \mu \mathrm{l})$ was treated with $5 \%$ trichloroacetic acid (TCA; Sigma-Aldrich, Munich, Germany) (1:1 v/v), vortexed and centrifuged at $28,000 \mathrm{x}$ g for $5 \mathrm{~min}$ at $4^{\circ} \mathrm{C}$. The supernatants were then removed and the procedure was repeated in the same manner. Subsequently, the clear supernatants were transferred to new Eppendorf tubes and were used for the determination of GSH levels. Plasma and erythrocyte lysates were stored at $-80^{\circ} \mathrm{C}$ until further analysis.
Assessment of weight, $B F$ and RQ. Weight, BF\% determination, and RQ measurements were performed after $3 \mathrm{~h}$ of complete fasting during the visit of the individuals. RQ at rest and the average RQ of walking were measurement following the BRUCE protocol (stress test), up to 140 pulses (19). All individuals measured have normal sleep, $24 \mathrm{~h}$ abstinence from physical exercise, $3 \mathrm{~h}$ from smoking and coffee drinking and they had not been ill or followed a specific diet in the last 7 days. The weight was calculated with high accuracy weight scale, the percentage of BF was determined with the use of a dermatometer and the RQ was counted using an ergospirometer. The ergospirometer measures the amount of oxygen in the inhaled and exhaled air. Finally, the volume of intake oxygen $\left(\mathrm{VO}_{2}\right)$ is calculated based on which the basal metabolic rate is measured. The ergospirometer also measures carbon dioxide rates in the inhaled and exhaled air as well as the RQ, that is the ratio of carbon dioxide to oxygen $\left(\mathrm{CO}_{2} / \mathrm{VO}_{2}\right)$ indicating the proportion of energy generated by the contribution of carbohydrates and fats.

Assessment of oxidative status markers TBARS, and GSH. For the determination of the TBARS levels, the assay was based on the method described in the study by Keles et al (20). TBARS is a commonly and frequently used method to determine lipid peroxidation. According to this method, $100 \mu \mathrm{l}$ of plasma were mixed with $500 \mu \mathrm{l}$ of $35 \%$ TCA (Merck KGaA, Darmstadt, Germany) and $500 \mu \mathrm{l}$ of Tris- $\mathrm{HCl}$ (Sigma-Aldrich, St. Louis, MO, USA; $200 \mathrm{mM}, \mathrm{pH}$ 7.4) and incubated for $10 \mathrm{~min}$ at room temperature. One milliliter of $2 \mathrm{M}$ sodium sulfate $\left(\mathrm{Na}_{2} \mathrm{SO}_{4}\right)$ and $55 \mathrm{mM}$ thiobarbituric acid (TBA) solution were added and the samples were incubated at $95^{\circ} \mathrm{C}$ for $45 \mathrm{~min}$. The samples were cooled on ice for $5 \mathrm{~min}$ and were vortexed following the addition of $1 \mathrm{ml}$ of $70 \%$ TCA. The samples were centrifuged at $15,000 \mathrm{x} \mathrm{g}$ for $3 \mathrm{~min}$ and the absorbance of the supernatant was read at $530 \mathrm{~nm}$ using a spectrophotometer (Hitachi U-1900; serial no. 2023-029; Hitachi, Tokyo, Japan). A baseline absorbance was taken into account by running a blank along with all samples during the measurement. The calculation of the TBARS concentration was based on the molar extinction coefficient of malondialdehyde.

The concentration of CARB, an index of protein oxidation, was determined based on the method described in the study by Patsoukis et al (21). In this assay, $50 \mu \mathrm{l}$ of $20 \%$ TCA were added to $50 \mu \mathrm{l}$ of plasma and this mixture was incubated in an ice bath for $15 \mathrm{~min}$ and centrifuged at $15,000 \mathrm{x} \mathrm{g}$ for $5 \mathrm{~min}$ at $4^{\circ} \mathrm{C}$. The supernatant was discarded and $500 \mu \mathrm{l}$ of $10 \mathrm{mM}$ 2,4-dinitrophenylhydrazine (DNPH; Sigma-Aldrich, Munich, Germany) (in $2.5 \mathrm{~N} \mathrm{HCl}$ ) for the sample, or $500 \mu 1$ of $2.5 \mathrm{~N} \mathrm{HCl}$ for the blank, were added to the pellet. The samples were incubated in the dark at room temperature for $1 \mathrm{~h}$ with intermittent vortexing every $15 \mathrm{~min}$ and were centrifuged at $15,000 \mathrm{xg}$ for $5 \mathrm{~min}$ at $4^{\circ} \mathrm{C}$. The supernatant was discarded and $1 \mathrm{ml}$ of $10 \%$ TCA was added, vortexed and centrifuged at $15,000 \mathrm{x}$ g for $5 \mathrm{~min}$ at $4^{\circ} \mathrm{C}$. The supernatant was discarded and $1 \mathrm{ml}$ of ethanol-ethyl acetate $(1: 1 \mathrm{v} / \mathrm{v})$ was added, vortexed and centrifuged at 15,000 x $\mathrm{g}$ for $5 \mathrm{~min}$ at $4^{\circ} \mathrm{C}$. This washing step was repeated twice. The supernatant was discarded and $1 \mathrm{ml}$ of $5 \mathrm{M}$ urea ( $\mathrm{pH} 2.3$ ) was added, vortexed and incubated at $37^{\circ} \mathrm{C}$ for $15 \mathrm{~min}$. The samples were centrifuged at $15,000 \mathrm{x} \mathrm{g}$ for $3 \mathrm{~min}$ at $4^{\circ} \mathrm{C}$ and the absorbance was read at $375 \mathrm{~nm}$. The calculation of the CARB concentration was based on the molar extinction coefficient of DNPH. 
Table I. Values of redox status biomarkers, RQ, weight and BF\% before and after the intervention.

\begin{tabular}{lccr}
\hline Parameters & PRE $($ mean \pm SEM) & POST (mean \pm SEM) & $\%$ of PRE \\
\hline GSH $(\mu \mathrm{mol} / \mathrm{g} \mathrm{Hb})$ & $3.75 \pm 0.11$ & $2.64 \pm 0.10^{\mathrm{c}}$ & $71.26 \pm 1.95^{\mathrm{c}}$ \\
CARB $(\mathrm{nmol} / \mathrm{mg}$ protein) & $0.51 \pm 0.01$ & $0.53 \pm 0.01$ & $109.1 \pm 3.26$ \\
TBARS $(\mu \mathrm{mol} / \mathrm{l}$ plasma) & $5.26 \pm 0.13$ & $5.32 \pm 0.11$ & $107.47 \pm 3.68$ \\
RQ & $0.90 \pm 0.03$ & $0.78 \pm 0.01^{\mathrm{b}}$ & $89.97 \pm 2.70^{\mathrm{b}}$ \\
Weight $(\mathrm{kg})$ & $83.33 \pm 2.63$ & $75.77 \pm 2.06^{\mathrm{a}}$ & $92.37 \pm 0.68^{\mathrm{c}}$ \\
BF\% & $30.70 \pm 0.89$ & $24.31 \pm 0.82^{\mathrm{c}}$ & $79.43 \pm 1.29^{\mathrm{c}}$
\end{tabular}

Changes are also shown percentages relative to PRE condition. ${ }^{a} \mathrm{P}<0.05,{ }^{\mathrm{b}} \mathrm{P}<0.01,{ }^{\mathrm{c}} \mathrm{P}<0.001$, significantly different compared to the pre-intervention condition. PRE, pre-intervention; POST, post-intervention; RQ, respiratory quotient; BF\%, body fat percentage; GSH, glutathione; CARB, protein carbonyls; TBARS, thiobarbituric acid reactive substances; SEM, standard error of the mean.

The GSH levels were measured based on the method previously described in the study by Reddy et al (22). A total of $20 \mu \mathrm{l}$ of erythrocyte lysate was treated with $5 \%$ TCA, mixed with $660 \mu \mathrm{l}$ of $67 \mathrm{mM}$ sodium potassium phosphate $(\mathrm{pH} 8)$ and $330 \mu \mathrm{l}$ of $1 \mathrm{mM}$ 5,5-dithiobis-2 nitrobenzoate (DTNB; Sigma-Aldrich, Munich, Germany). The samples were incubated in the dark at room temperature for $45 \mathrm{~min}$ and the absorbance was read at $412 \mathrm{~nm}$ using a spectrophotometer (Hitachi U-1900; serial no. 2023-029; Hitachi). The GSH concentration was calculated relative to a calibration curve made using commercial standards.

Diet and exercise intervention. From the evaluation of the results, a personalised aerobic exercise program was produced, whose frequency and intensity are the most important factors that affect the use of muscle glycogen and glucose uptake. Protocols of exercise differ in relation to RQ. Personalized nutrition therapy aimed at metabolic regulation and the use of fat stores as a primary energy source. The diet consisted of 6 meals per day, 3 main and 3 postprandial, in which the two main meals comprise of biofunctional food containing $10 \mathrm{~g}$ whey protein from ewe-goat milk, slow burning carbohydrates over $30 \%$ in their composition and are a source of fiber. For those with RQ $<0.7$, a 7 th meal was added before bedtime, rich in casein to $5 \%$ of BMR. Diet is based on a ratio of 30:50:20 macronutrients (proteins:carbohydrates:fats), based on the World Health Organization (WHO) guidelines for nutrition of patients with MetS. This composition is maintained both for every meal and for the whole day, aiming at any possible regulation of glycemic load (GL), which is benefited from frequent meals with specific caloric ratio. Food combinations contain a minimum of $25 \mathrm{~g}$ fiber for women and $35 \mathrm{~g}$ for men based on the WHO directive for patients of MetS.

Statistical analysis. For statistical analysis, data were analysed by one-way ANOVA followed by Dunnett's test for multiple pair wise comparisons. The level of statistical significance was set at $\mathrm{P}<0.05$. For all statistical analyses, SPSS software version 13.0 (SPSS, Inc., Chicago, IL, USA) was used. Data are presented as the means \pm SEM.

\section{Results}

The results revealed that the GSH values were significantly $(\mathrm{P}<0.001)$ lower by $29.7 \%$ in the subjects following dietary intervention, indicating an increase in oxidative stress (Table I). No statistically significant differences were observed in the CARB and TBARS levels in the plasma of the subjects before and after intervention. The RQ, weight and BF of the subjects decreased significantly by $10.03,7.63$ and $20.67 \%$ respectively.

In previous studies, we found that the induction of oxidative stress exhibited great variability between different individuals, since the outcome of an oxidant stimulus may be affected by several different factors (e.g., genetic, physiological and biochemical) $(18,23,24)$. Based on this observation, the individual variability of the tested oxidative stress markers within the patients with MetS and obesity was examined. Among these markers, the GSH marker exhibited the greatest variability, since there was a 6-fold difference between the lowest value and the highest value. In addition, GSH is considered one of the most important endogenous antioxidant molecules and a major contributor to the cellular redox status of living organisms (25). Thus, the patients with MetS and obesity were divided into 2 subgroups, the first one with low GSH levels ( $\mathrm{n}=44$; GSH $<3.5 \mu \mathrm{mol} / \mathrm{g} \mathrm{Hb}$ ) and the second one with high GSH levels ( $\mathrm{n}=59$; GSH $>3.5 \mu \mathrm{mol} / \mathrm{g} \mathrm{Hb}$ ). Between the average values of these 2 GSH groups, there was a statistically significant $(\mathrm{P}<0.001)$ difference (by $41.3 \%)$ in the GSH levels in erythrocytes (Table II). Moreover, in these 2 GSH groups, the differences between the other oxidative stress markers were also examined. There was a significant difference observed in CARB levels in plasma between the 2 GSH groups. CARB levels in the low GSH group were significantly increased by $28.6 \%$ compared with the high GSH group (Table II). The low GSH group exhibited higher levels of CARB and, as this group had reduced levels of GSH, it was exposed to greater levels of oxidative stress. No significant differences were observed in TBARS, RQ, weight and BF\% between the 2 GSH groups before intervention.

In both the high GSH and low GSH group after the intervention, the GSH levels, RQ, weight and BF\% were significantly decreased compared to pre-intervention. The CARB levels were significant increased only in the high GSH group compared to pre-intervention. In the high GSH group, the GSH levels were decreased by $31.62 \%$, RQ by $9.45 \%$, weight by $9.08 \%$ and $\mathrm{BF} \%$ by $23.63 \%$, whereas the CARB levels were increased by $10.36 \%$. In the low GSH group, the GSH levels were decreased by $24.89 \%$, RQ by $10.23 \%$, weight by $5.68 \%$ and BF\% by $19.73 \%$. 
Table II. Values of redox status biomarkers, RQ, weight and BF in high GSH and low GSH groups before and after intervention.

\begin{tabular}{lcccc}
\hline Parameters & $\begin{array}{c}\text { High GSH PRE } \\
(\text { mean } \pm \text { SEM })\end{array}$ & $\begin{array}{c}\text { High GSH POST } \\
(\text { mean } \pm \text { SEM) }\end{array}$ & $\begin{array}{c}\text { Low GSH PRE } \\
(\text { mean } \pm \text { SEM) }\end{array}$ & $\begin{array}{c}\text { Low GSH POST } \\
(\text { mean } \pm \text { SEM })\end{array}$ \\
\hline GSH $(\mu$ mol/g Hb) & $4.55 \pm 0.09$ & $3.11 \pm 0.13^{\mathrm{c}}$ & $2.67 \pm 0.08^{\mathrm{g}}$ & $2.01 \pm 0.11^{\mathrm{e}, \mathrm{h}}$ \\
CARB (nmol/mg protein) & $0.48 \pm 0.01$ & $0.52 \pm 0.01^{\mathrm{a}}$ & $0.54 \pm 0.02^{\mathrm{f}}$ & $0.54 \pm 0.02$ \\
TBARS $(\mu \mathrm{mol} / \mathrm{l}$ plasma) & $5.26 \pm 0.17$ & $5.26 \pm 0.15$ & $5.27 \pm 0.21$ & $5.39 \pm 0.17$ \\
RQ & $0.91 \pm 0.04$ & $0.76 \pm 0.01^{\mathrm{b}}$ & $0.88 \pm 0.06$ & $0.81 \pm 0.03$ \\
Weight $(\mathrm{kg})$ & $86.68 \pm 3.73$ & $77.65 \pm 2.89^{\mathrm{a}}$ & $78.83 \pm 3.57$ & $73.83 \pm 2.90$ \\
BF\% & $31.94 \pm 1.15$ & $24.78 \pm 1.06^{\mathrm{c}}$ & $29.57 \pm 1.35$ & $23.97 \pm 1.31^{\mathrm{d}}$ \\
\hline
\end{tabular}

${ }^{\mathrm{a}} \mathrm{P}<0.05,{ }^{\mathrm{b}} \mathrm{P}<0.01,{ }^{\mathrm{c}} \mathrm{P}<0.001$ significantly different between the HIGH GSH PRE and the HIGH GSH POST groups; ${ }^{\mathrm{d}} \mathrm{P}<0.01,{ }^{\mathrm{e}} \mathrm{P}<0.001$ significantly different between the LOW GSH PRE and the LOW GSH POST groups; ${ }^{\mathrm{P}}<0.05$, ${ }^{\mathrm{g}} \mathrm{P}<0.001$ significantly different between the HIGH GSH PRE and the LOW GSH PRE groups; ${ }^{\mathrm{P}}<0.001$ significantly different between the HIGH GSH POST and the LOW GSH POST groups; PRE, preintervention; POST, post-intervention; RQ, respiratory quotient; BF, body fat; GSH, glutathione; CARB, protein carbonyls; TBARS, thiobarbituric acid reactive substances; SEM, standard error of the mean.

Table III. Percentage of PRE values of redox status biomarkers, $\mathrm{RQ}$, weight and BF in high GSH and low GSH groups after intervention.

\begin{tabular}{lcc}
\hline & $\begin{array}{c}\text { High GSH POST } \\
\text { (as of High GSH PRE, } \\
\text { mean } \pm \text { SEM) }\end{array}$ & $\begin{array}{c}\text { Low GSH POST } \\
\text { (as \% of Low GSH PRE, } \\
\text { (mean } \pm \text { SEM) }\end{array}$ \\
\hline GSH & $68.38 \pm 1.93^{\mathrm{c}}$ & $75.11 \pm 1.92^{\mathrm{c}, \mathrm{d}}$ \\
CARB & $110.36 \pm 3.80^{\mathrm{a}}$ & $105.54 \pm 4.40$ \\
TBARS & $106.60 \pm 3.86$ & $108.65 \pm 3.46$ \\
RQ & $90.55 \pm 2.32^{\mathrm{a}}$ & $89.77 \pm 3.20^{\mathrm{a}}$ \\
Weight & $90.92 \pm 0.70^{\mathrm{c}}$ & $94.32 \pm 0.61^{\mathrm{c}, \mathrm{d}}$ \\
BF & $76.27 \pm 1.17^{\mathrm{c}}$ & $80.27 \pm 1.06^{\mathrm{c}, \mathrm{d}}$ \\
\hline
\end{tabular}

${ }^{\mathrm{a}} \mathrm{P}<0.05,{ }^{\mathrm{b}} \mathrm{P}<0.01,{ }^{\mathrm{c}} \mathrm{P}<0.001$, significantly different between $\mathrm{PRE}$ and POST condition. ${ }^{\mathrm{d}} \mathrm{P}<0.01$, significantly different between two groups. PRE, pre-intervention; POST, post-intervention; RQ, respiratory quotient; BF, body fat; GSH, glutathione; TBARS, thiobarbituric acid reactive substances; SEM, standard error of the mean.

The following differences were also observed between the 2 GSH groups: The high GSH group exhibited a significant reduction in GSH levels compared with the low GSH group. Furthermore, the high GSH group exhibited a significant reduction in weight and $\mathrm{BF} \%$ compared to the low GSH group (Table III).

\section{Discussion}

MetS is a relatively new pathological condition, which is based on the observation that a number of cardiovascular risk factors, such as obesity, type 2 diabetes, arterial hypertension and dyslipidemia, co-exist in the same individual. The criteria for MetS by NCEP III are as follows: A waist circumference of $>102 \mathrm{~cm}$ for men and $>88 \mathrm{~cm}$ for women, triglyceride levels $\geq 150 \mathrm{mg} / \mathrm{dl}$, HDL levels $<40 \mathrm{mg} / \mathrm{dl}$ for men and $<50 \mathrm{mg} / \mathrm{dl}$ for women, blood pressure (systolic $\geq 130$ or diastolic $\geq 85 \mathrm{mmHg}$ ) and fasting plasma glucose levels $\geq 110 \mathrm{mg} / \mathrm{dl}$. An individual is defined as suffering from MetS if she/he displays pathological values in three or more of the above-mentioned factors $(26,27)$. The basic disorder indicating MetS is the insulin resistance of tissues, particularly the muscles, liver and adipose tissue, indicating the reduced activity of insulin in these organs $(13,28,29)$. The main cause of this phenomenon is obesity, particularly the central type, which is obesity characterized by significant fat deposition in the abdomen and mainly intra-abdominal fat deposition. Other predisposing factors, and hence the causes of MetS, are heredity, an increased dietary intake of calories, particularly those derived from fat and sugars, reduced physical activity, increasing age and smoking (30-33). The higher the age of the individual, the higher the risk of developing MetS, as with increasing age, diabetes, dyslipidemia, hypertension and central type obesity occur more frequently (33).

The causative and most important treatment for MetS is weight loss. Weight loss improves both individual metabolic disorders (glucose levels, pressure and lipids), but mainly improves insulin resistance and therefore acts on the cause of the problem (34-37). An increase in physical activity either in the form of exercise or in the form of an increase in daily routine activities has the same ameliorating effect $(34,37)$. Drugs that aid weight loss can be used successfully. Medications that improve insulin resistance are metformin and glitazones, which are approved and used only as antidiabetic drugs (38-40).

MetS, obesity and diabetes are disorders associated with increased oxidative stress. Oxidative stress is a pathophysiological condition in which there is an imbalance between free radical production and antioxidant mechanisms $(13,14,41)$. Oxidative stress appearing in patients with MetS, diabetes and obesity may further deteriorate the associated complications and in particular those involved with the cardiovascular system $(15,17)$. Thus, the assessment of oxidative stress in patients with MetS and diabetes is considered useful for monitoring their health status $(42,43)$. Previous studies by our research group investigated the levels of oxidative stress in people suffering from MetS and obesity $(18,44,45)$. In one of these studies, Spanidis et al (18) analysed the levels of oxidative stress in individuals suffering from MetS; the results revealed that patients could be divided into two subgroups depending on the levels of GSH, which is an antioxidant molecule. There 
were patients with low GSH levels, but also patients with higher GSH levels. GSH is one of the most important antioxidant mechanisms in living organisms, and thus low GSH levels are associated with oxidative stress and the manifestation of various diseases $(46,47)$. The aim of this study was to investigate the effects of redox status levels on the ability of patients to lose weight following dietary therapy and exercise.

The results revealed that patients with MetS experienced significant changes in their body composition following dietary therapy and the addition of exercise to their daily routine for a 6-month period. In particular, a significant weight loss and reduction in BF\% were observed by 8.63 and $20.57 \%$, respectively. At the same time, their RQ was significantly improved as the average of 0.90 became 0.78 . The above-mentioned data indicate an improvement in the metabolic condition of patients with beneficial health effects. It is known that weight loss and body fat loss are an important factor in improving the status of obesity and MetS (34-38). In addition, an improvement in RQ indicates the change in the metabolic capacity of patients to use fat as a source of energy while at rest $(48,49)$. As regards the redox status markers, no significant changes in the levels of CARB and TBARS were observed, although a significant decrease in GSH levels was observed. As already mentioned, GSH is one of the most important cellular antioxidants. While increased levels of GSH may exert protective effects against a number of diseases, decreased levels of GSH increase energy expenditure, prevent obesity and reduce insulin resistance $(50,51)$. Existing data suggest that decreased GSH levels activates the nuclear factor (erythroid-derived 2)-like 2 (Nrf2) transcription factor pathway. The Nrf2/antioxidant response element pathway is a redox-sensing mechanism linking changes in cellular redox status to the expression of genes whose resulting proteins regulate the energy metabolism and metabolism of ROS and products of ROS damage. As such, recent data connect the Nrf2/antioxidant response element pathway to GSH depletion, obesity, increases in energy metabolism and decreases in lipid deposition (51-53).

Taking into account the findings of our previous study, with the great fluctuations in GSH levels between the individuals (18), two subgroups of patients were observed and distinguished: One with high GSH levels $(>3.5 \mu \mathrm{mol} / \mathrm{g} \mathrm{Hb})$ and one with low GSH levels $(<3.5 \mu \mathrm{mol} / \mathrm{g} \mathrm{Hb})$. The two subgroups were examined for the remaining redox status markers, body weight, BF\% and RQ. No significant differences were observed in weight, RQ and BF\% between the two groups. In addition, no differences in TBARS were observed; however, a significant increase in CARB levels was observed in the low GSH group compared with the high GSH group, indicating that the low GSH group was exposed to increased oxidative stress.

Examining the markers in the 2 groups following a 6-month period of personalized treatment with specific diet and exercise, the following findings were observed: In both groups, the body weight and BF\% were reduced and RQ was improved. In addition, in both groups, the GSH levels were decreased, whereas only in the high GSH group, the CARB levels were increased significantly. The decrease in GSH levels was significantly higher in the high GSH group, as GSH levels decreased by $31.62 \%$, while in the low GSH group by $24.89 \%$. Among the groups, there was significantly greater weight and BF loss in the high GSH group. Specifically, the high GSH group lost $9.08 \%$ of the weight and $23.63 \%$ of the $\mathrm{BF}$, as opposed to the low GSH group, which lost $5.68 \%$ of the weight and $19.73 \%$ of the $\mathrm{BF}$, respectively. It was therefore observed that the addition of exercise and dietary therapy improved weight and BF in both groups, although patients with higher GSH values appeared to be more profitable, probably due to a greater decrease in GSH levels. This finding is of particularly importance as it indicates that it is useful to determine the redox status markers in patients with MetS as they may prove to be helpful in providing personalized dietary therapy.

An increasing number of studies in recent years have come to the conclusion that diabetes and other metabolic diseases such as MetS and obesity are redox diseases (54-57). Type 2 diabetes is the final stage at which a pre-diabetic subject will come to within time if the problem is not reversed. MetS and obesity are characterized as primary pre-diabetic conditions, where insulin sensitivity is gradually reduced and hyperglycemia and insulin resistance appear (54,57). First, Watson (57) developed the theory that there is a disorder in the redox balance in diabetic cells. Specifically, a reductive environmental induction in the endoplasmic cell reticulum affects the folding of protein; thus they do not acquire the correct tertiary structure, thus losing their functionality, leading to a decrease in the sensitivity of insulin and ultimately to insulin resistance (57).

Lately, a number of studies have highlighted the benefit of reducing GSH levels in weight loss. In studies using knockout mice for the modifier subunit of glutamate cysteine ligase (GCLM), it was shown that GSH levels decreased by $20 \%$, while theses mice were resistant to insulin resistance, had hyperglycemia and an increased metabolic rate compared to the wild-type mice. At the same time, the specific mice exhibited an increased activity of mitochondrial complex I and reduced lipid synthesis in the liver (58). In studies where pharmaceutical GCL inhibitors were used, similar effects were observed $(50,59)$. These data suggest that GSH, perhaps through the regulation of redox-sensitive proteins, regulates energy metabolism. One of these is the Nrf-2 transcription factor. It is known that reduced levels of GSH increase its activity in the nucleus, where it can activate a series of genes associated with increased metabolism $(52,60)$. Experiments that have been carried out and resulted in Nrf-2 activation in animals have demonstrated an increase in insulin sensitivity and a reduced chance of developing obesity after a high fat diet (61). Induction in certain studies was mainly mediated by Nrf-2 agonists, such as curcumin and resveratrol $(62,63)$. The exact opposite effects were observed when the effect of Nrf-2 was inhibited. Therefore, a decrease in GSH activates metabolism indirectly by increasing the activity of Nrf-2.

In addition to GSH levels, GSH metabolic enzymes, such as Gpx, glutathione reductase (Grx) and glutathione S-transferase (GST) play a key role in the development of obesity and insulin resistance. A particular role appears to be played by the GPx1 isoform, where its overexpression promotes insulin resistance and obesity (64-66). It has been have demonstrated that there are polymorphisms in the GPx1 gene associated with the overexpression and occurrence of MetS (67). Gpx uses GSH by oxidizing it in order to reduce hydrogen peroxide or lipid hydroperoxides. Genetic diversity of this gene in combination with eating habits can affect GSH levels in the body. In addition, the role of S-glutathionylation in mitochondrial 
metabolism seems to be significant. S-glutathionylation, through GRX, inhibits the action of hydrogen peroxide or lipid hydroperoxides, thus reducing aerobic metabolism (68-70). In addition, the GST gene appears to be highly polymorphic in humans. Defective alleles in GSTM1 or GSTT1 are associated with an increased chance of developing diabetes type $2(71,72)$. Thus, GSH levels combined with the availability and activity of these enzymes play a key role in the development of insulin resistance and obesity.

In this study, it was observed that the marker with the greater fluctuations in its levels was GSH, a small thiol sensitive to changes in the redox environment. Differences in the redox status of individuals in the 2 groups are indicated by differences in GSH levels. However, the 2 groups with high or low GSH did not differ in weight and $\mathrm{BF} \%$ before intervention. This particular diet applied alongside the exercise program affected the reductive environment by lowering the GSH levels. This reduction probably regulated the disrupted redox status of patients, leading to weight and BF loss and in regulating glucose metabolism. However, the response to the intervention was better when the initial GSH levels were higher. The fact that there is a wide variation in GSH levels in patients with MetS is probably due to intercourse eating habits, but also to the genetic background as discussed above. However, patients with high GSH levels appeared to respond better to the intervention. In particular, the GSH pool appears to be sufficient so that a reduction in these levels is not related to the negative effects of oxidative stress. On the contrary, when the GSH levels are already low, it is difficult to reduce these levels further as there is already an oxidizing environment. Additional studies on these 2 classes of individuals with MetS would explain the role of GSH levels along with other factors, such as the activity of GSH-dependent enzymes in weight loss and the improved metabolic status of patients.

It is interesting to further investigate whether individuals with low GSH levels can increase their antioxidant capacity with dietary intervention and then proceed to a dietary plan for weight loss. A possible method with which to increase GSH levels may be a diet rich in antioxidants. Studies have demonstrated that the administration of pomegranate juice rich in polyphenols and the administration of foods rich in eye-goat whey protein serum have led to an increase in GSH levels in humans $(73,74)$. It is of great interest to examine whether these individuals can increase their GSH levels through diet and then whether it would be easier to lose weight with a similar dietary intervention.

In conclusion, the results of this study demonstrate the significance of the determination the oxidative status markers in patients with MetS, obesity and diabetes. In particular, the GSH levels are an important indicator of the reductive environment of the cells and its determination has great significance to the above-mentioned patients. Determining GSH levels before and during a nutritional intervention in diabetics and pre-diabetics may provide useful information on the condition and course of treatment, which may aid specialists in providing a better plan on individualized intervention in these patients.

\section{Acknowledgements}

Not applicable.

\section{Funding}

No funding was received.

\section{Availability of data and materials}

All data generated or analyzed during this study are included in this published article.

\section{Authors' contributions}

NG and MO wrote the manuscript. NG conducted the redox status biomarkers assays. GL and IC collected the anthropometric parameters and designed the individualized intervention. NG and MO carried out the statistical analysis. DK and DAS conceived and designed the study, and supervised the study. All authors have read and approved the final manuscript.

\section{Ethics approval and consent to participate}

All experimental procedures were performed in accordance with the European Union Guidelines laid down in the 1964 Declaration of Helsinki and were approved by the Institutional Review Board of the University of Thessaly (Larissa, Greece).

\section{Consent for publication}

Not applicable.

\section{Competing interests}

DAS is the Editor-in-Chief for the journal, but had no personal involvement in the reviewing process, or any influence in terms of adjudicating on the final decision, for this article.

\section{References}

1. Scuteri A, Laurent S, Cucca F, Cockcroft J, Cunha PG, Mañas LR, Mattace Raso FU, Muiesan ML, Ryliškytė L, Rietzschel E, et al; Metabolic Syndrome and Arteries Research (MARE) Consortium: Metabolic syndrome across Europe: Different clusters of risk factors. Eur J Prev Cardiol 22: 486-491, 2015.

2. Moore JX, Chaudhary N and Akinyemiju T: Metabolic syndrome prevalence by race/ethnicity and sex in the United States, National Health and Nutrition Examination Survey, 1988-2012. Prev Chronic Dis 14: E24, 2017.

3. Kaur J: A comprehensive review on metabolic syndrome. Cardiol Res Pract 2014: 943162, 2014.

4. Felizola SJA: Ursolic acid in experimental models and human subjects: Potential as an anti-obesity/overweight treatment? doi: 10.13140/RG.2.1.4502.4804, 2015.

5. De Sousa SM and Norman RJ: Metabolic syndrome, diet and exercise. Best Pract Res Clin Obstet Gynaecol 37: 140-151, 2016.

6. Root MM and Dawson HR: DASH-like diets high in protein or monounsaturated fats improve metabolic syndrome and calculated vascular risk. Int J Vitam Nutr Res 83: 224-231, 2013.

7. Sofer S, Stark AH and Madar Z: Nutrition targeting by food timing: Time-related dietary approaches to combat obesity and metabolic syndrome. Adv Nutr 6: 214-223, 2015.

8. Halliwell B: The wanderings of a free radical. Free Radic Biol Med 46: 531-542, 2009.

9. Ghosh J and Myers CE: Inhibition of arachidonate 5-lipoxygenase triggers massive apoptosis in human prostate cancer cells. Proc Natl Acad Sci USA 95: 13182-13187, 1998.

10. Valko M,Leibfritz D, Moncol J, Cronin MT, Mazur M and Telser J: Free radicals and antioxidants in normal physiological functions and human disease. Int J Biochem Cell Biol 39: 44-84, 2007. 
11. Orient A, Donkó A, Szabó A, Leto TL and Geiszt M: Novel sources of reactive oxygen species in the human body. Nephrol Dial Transplant 22: 1281-1288, 2007.

12. Mylonas C and Kouretas D: Lipid peroxidation and tissue damage. In Vivo 13: 295-309, 1999.

13. Nikooyeh B and Neyestani TR: Oxidative stress, type 2 diabetes and vitamin D: Past, present and future. Diabetes Metab Res Rev 32: 260-267, 2016.

14. Giacco F and Brownlee M: Oxidative stress and diabetic complications. Circ Res 107: 1058-1070, 2010.

15. Folli F, Corradi D, Fanti P, Davalli A, Paez A, Giaccari A, Perego C and Muscogiuri G: The role of oxidative stress in the pathogenesis of type 2 diabetes mellitus micro- and macrovascular complications: Avenues for a mechanistic-based therapeutic approach Curr Diabetes Rev 7: 313-324, 2011.

16. Ha CY, Kim JY, Paik JK, Kim OY, Paik YH, Lee EJ and Lee JH: The association of specific metabolites of lipid metabolism with markers of oxidative stress, inflammation and arterial stiffness in men with newly diagnosed type 2 diabetes. Clin Endocrinol (Oxf) 76: 674-682, 2012.

17. Aroor AR and DeMarco VG: Oxidative stress and obesity: The chicken or the egg? Diabetes 63: 2216-2218, 2014.

18. Spanidis Y, Mpesios A, Stagos D, Goutzourelas N, Bar-Or D, Karapetsa M, Zakynthinos E, Spandidos DA, Tsatsakis AM, Leon G and Kouretas D: Assessment of the redox status in patients with metabolic syndrome and type 2 diabetes reveals great variations. Exp Ther Med 11: 895-903, 2016.

19. Sarma S and Levine BD: Beyond the Bruce Protocol: Advanced Exercise Testing for the Sports Cardiologist. Cardiol Clin 34 603-608, 2016.

20. Keles MS, Taysi S, Sen N, Aksoy H and Akçay F: Effect of corticosteroid therapy on serum and CSF malondialdehyde and antioxidant proteins in multiple sclerosis. Can J Neurol Sci 28: 141-143, 2001

21. Patsoukis N, Zervoudakis G, Panagopoulos NT, Georgiou CD, Angelatou F and Matsokis NA: Thiol redox state (TRS) and oxidative stress in the mouse hippocampus after pentylenetetrazol-induced epileptic seizure. Neurosci Lett 357: 83-86, 2004.

22. Reddy YN, Murthy SV, Krishna DR and Prabhakar MC: Role of free radicals and antioxidants in tuberculosis patients. Indian J Tuberc 51: 213-218, 2004

23. Stagos D, Goutzourelas N, Ntontou AM, Kafantaris I, Deli CK, Poulios A, Jamurtas AZ, Bar-Or D and Kouretas D: Assessment of eccentric exercise-induced oxidative stress using oxidationreduction potential markers. Oxid Med Cell Longev 2015 204615, 2015.

24. Bloomer RJ and Fisher-Wellman KH: Blood oxidative stress biomarkers: Influence of sex, exercise training status, and dietary intake. Gend Med 5: 218-228, 2008

25. Deponte M: Glutathione catalysis and the reaction mechanisms of glutathione-dependent enzymes. Biochim Biophys Acta 1830 3217-3266, 2013.

26. Wilson PWF and Grundy SM: The metabolic syndrome: practical guide to origins and treatment: Part I. Circulation 108: $1422-1424,2003$

27. Balkau B,Charles MA, Drivsholm T, Borch-Johnsen K, Wareham N, Yudkin JS, Morris R, Zavaroni I, van Dam R, Feskins E, et al; European Group For The Study Of Insulin Resistance (EGIR): Frequency of the WHO metabolic syndrome in European cohorts, and an alternative definition of an insulin resistance syndrome. Diabetes Metab 28: 364-376, 2002.

28. Bulló M, Cózar-Torrell P and Salas-Salvadó J: Dietary regulation of glucose metabolism in metabolic syndrome. Curr Vasc Pharmacol 11: 928-945, 2013.

29. Roberts CK, Hevener AL and Barnard RJ: Metabolic syndrome and insulin resistance: Underlying causes and modification by exercise training. Compr Physiol 3: 1-58, 2013.

30. Bouret S, Levin BE and Ozanne SE: Gene-environment interactions controlling energy and glucose homeostasis and the developmental origins of obesity. Physiol Rev 95: 47-82, 2015.

31. Adamo KB, Ferraro ZM and Brett KE: Can we modify the intrauterine environment to halt the intergenerational cycle of obesity? Int J Environ Res Public Health 9: 1263-1307, 2012.

32. Keane D, Kelly S, Healy NP, McArdle MA, Holohan K and Roche HM: Diet and metabolic syndrome: An overview. Curr Vasc Pharmacol 11: 842-857, 2013.

33. Sutin AR, Costa PT Jr, Uda M, Ferrucci L, Schlessinger D and Terracciano A: Personality and metabolic syndrome. Age (Dordr) 32: 513-519, 2010.
34. Ferland A and Eckel RH: Does sustained weight loss reverse the metabolic syndrome? Curr Hypertens Rep 13: 456-464, 2011.

35. Ades PA and Savage PD: Potential benefits of weight loss in coronary heart disease. Prog Cardiovasc Dis 56: 448-456, 2014.

36. Abete I, Astrup A, Martínez JA, Thorsdottir I and Zulet MA Obesity and the metabolic syndrome: Role of different dietary macronutrient distribution patterns and specific nutritional components on weight loss and maintenance. Nutr Rev 68 214-231, 2010.

37. Strasser B: Physical activity in obesity and metabolic syndrome. Ann N Y Acad Sci 1281: 141-159, 2013.

38. Emili A, Abushomar $\mathrm{H}$ and Nair K: Treating metabolic syndrome: Lifestyle change or medication? Can Fam Physician 53: 1203-1205, 2007.

39. Wikner C, Gigante B, Hellénius ML, de Faire U and Leander K: The risk of type 2 diabetes in men is synergistically affected by parental history of diabetes and overweight. PLoS One 8: e61763, 2013.

40. Thangavel N, Al Bratty M, Akhtar Javed S, Ahsan W and Alhazmi HA: Targeting peroxisome proliferator-activated receptors using thiazolidinediones: Strategy for design of novel antidiabetic drugs. Int J Med Chem 2017: 1069718, 2017.

41. Hutcheson R and Rocic P: The metabolic syndrome, oxidative stress, environment, and cardiovascular disease: The great exploration. Exp Diabetes Res 2012: 271028, 2012.

42. Neyestani TR, Shariatzadeh N, Gharavi A, Kalayi A and Khalaji N: Physiological dose of lycopene suppressed oxidative stress and enhanced serum levels of immunoglobulin $\mathrm{M}$ in patients with type 2 diabetes mellitus: A possible role in the prevention of long-term complications. J Endocrinol Invest 30: 833-838, 2007.

43. Akbar S, Bellary S and Griffiths HR: Dietary antioxidant interventions in type 2 diabetes patients: A meta-analysis. Br J Diabetes Vasc Dis 11: 62-68, 2011.

44. Spanidis Y, Goutzourelas N, Stagos D, Kolyva AS, Gogos CA, Bar-Or D and Kouretas D: Assessment of oxidative stress in septic and obese patients using markers of oxidation-reduction potential. In Vivo 29: 595-600, 2015.

45. Kolyva AS, Zolota V, Mpatsoulis D, Skroubis G, Solomou EE, Habeos IG, Assimakopoulos SF, Goutzourelas N, Kouretas D and Gogos CA: The role of obesity in the immune response during sepsis. Nutr Diabetes 4: e137, 2014.

46. Mazzetti AP, Fiorile MC,Primavera A and Lo Bello M: Glutathione transferases and neurodegenerative diseases. Neurochem Int 82: $10-18,2015$

47. Pérez S, Pereda J, Sabater L and Sastre J: Redox signaling in acute pancreatitis. Redox Biol 5: 1-14, 2015

48. Nogiec C, Burkart A, Dreyfuss JM, Lerin C, Kasif S and Patti ME: Metabolic modeling of muscle metabolism identifies key reactions linked to insulin resistance phenotypes. Mol Metab 4: 151-163, 2015.

49. Jumpertz R, Guijarro A, Pratley RE, Mason CC, Piomelli D and Krakoff J: Associations of fatty acids in cerebrospinal fluid with peripheral glucose concentrations and energy metabolism. PLoS One 7: e41503, 2012

50. Findeisen HM, Gizard F, Zhao Y, Qing H, Jones KL, Cohn D, Heywood EB and Bruemmer D: Glutathione depletion prevents diet-induced obesity and enhances insulin sensitivity. Obesity (Silver Spring) 19: 2429-2432, 2011.

51. Picklo MJ, Long EK and Vomhof-DeKrey EE: Glutathionyl systems and metabolic dysfunction in obesity. Nutr Rev 73: 858-868, 2015

52. Vomhof-Dekrey EE and Picklo MJ Sr: The Nrf2-antioxidant response element pathway: A target for regulating energy metabolism. J Nutr Biochem 23: 1201-1206, 2012.

53. Seo HA and Lee IK: The role of Nrf2: Adipocyte differentiation, obesity, and insulin resistance. Oxid Med Cell Longev 2013: 184598,2013

54. Jiménez-Osorio AS,Picazo A, González-Reyes S,Barrera-Oviedo D, Rodríguez-Arellano ME and Pedraza-Chaverri J: Nrf2 and redox status in prediabetic and diabetic patients. Int J Mol Sci 15: 20290-20305, 2014

55. Liu X and Fang F: Type 2 diabetes caused by reductive redox potential? Sci China Life Sci 57: 729-730, 2014.

56. Erol A: Type 2 diabetes and cancer as redox diseases? Lancet 384 : 853-854, 2014.

57. Watson JD: Type 2 diabetes as a redox disease. Lancet 383: 841-843, 2014

58. Kendig EL, Chen Y, Krishan M, Johansson E, Schneider SN, Genter MB, Nebert DW and Shertzer HG: Lipid metabolism and body composition in Gclm(-/-) mice. Toxicol Appl Pharmacol 257: 338-348, 2011. 
59. Griffith OW and Meister A: Potent and specific inhibition of glutathione synthesis by buthionine sulfoximine (S-n-butyl homocysteine sulfoximine). J Biol Chem 254: 7558-7560, 1979.

60. Lin AH, Chen HW, Liu CT, Tsai CW and Lii CK: Activation of Nrf2 is required for up-regulation of the $\pi$ class of glutathione S-transferase in rat primary hepatocytes with L-methionine starvation. J Agric Food Chem 60: 6537-6545, 2012

61. Pi J,Leung L, Xue P, Wang W, Hou Y, Liu D, Yehuda-Shnaidman E, Lee C, Lau J, Kurtz TW, et al: Deficiency in the nuclear factor E2-related factor-2 transcription factor results in impaired adipogenesis and protects against diet-induced obesity. J Biol Chem 285: 9292-9300, 2010.

62. Shehzad A, Ha T, Subhan F and Lee YS: New mechanisms and the anti-inflammatory role of curcumin in obesity and obesityrelated metabolic diseases. Eur J Nutr 50: 151-161, 2011.

63. Shibata T, Kimura Y, Mukai A, Mori H, Ito S, Asaka Y, Oe S, Tanaka H, Takahashi T and Uchida K: Transthiocarbamoylation of proteins by thiolated isothiocyanates. J Biol Chem 286 : 42150-42161, 2011.

64. McClung JP, Roneker CA, Mu W, Lisk DJ, Langlais P, Liu F and Lei XG: Development of insulin resistance and obesity in mice overexpressing cellular glutathione peroxidase. Proc Natl Acad Sci USA 101: 8852-8857, 2004.

65. Wang X, Vatamaniuk MZ, Roneker CA, Pepper MP, Hu LG, Simmons RA and Lei XG: Knockouts of SOD1 and GPX1 exert different impacts on murine islet function and pancreatic integrity. Antioxid Redox Signal 14: 391-401, 2011.

66. Wang XD, Vatamaniuk MZ, Wang SK, Roneker CA, Simmons RA and Lei XG: Molecular mechanisms for hyperinsulinaemia induced by overproduction of selenium-dependent glutathione peroxidase-1 in mice. Diabetologia 51: 1515-1524, 2008.

67. Kuzuya M, Ando F, Iguchi A and Shimokata H: Glutathione peroxidase 1 Pro198Leu variant contributes to the metabolic syndrome in men in a large Japanese cohort. Am J Clin Nutr 87: 1939-1944, 2008.

68. Applegate MA, Humphries KM and Szweda LI: Reversible inhibition of alpha-ketoglutarate dehydrogenase by hydrogen peroxide: Glutathionylation and protection of lipoic acid. Biochemistry 47: 473-478, 2008 .
69. Kil IS and ParkJW: Regulation of mitochondrial NADP ${ }^{+}$-dependent isocitrate dehydrogenase activity by glutathionylation. J Biol Chem 280: 10846-10854, 2005.

70. McLain AL,Cormier PJ,KinterM and SzwedaLI: Glutathionylation of $\alpha$-ketoglutarate dehydrogenase: The chemical nature and relative susceptibility of the cofactor lipoic acid to modification. Free Radic Biol Med 61: 161-169, 2013.

71. Bid HK, Konwar R, Saxena M, Chaudhari P, Agrawal CG and Banerjee M: Association of glutathione S-transferase (GSTM1, $\mathrm{T} 1$ and $\mathrm{P} 1$ ) gene polymorphisms with type 2 diabetes mellitus in north Indian population. J Postgrad Med 56: 176-181, 2010.

72. Tang ST, Wang CJ, Tang HQ, Zhang Q and Wang Y: Evaluation of glutathione S-transferase genetic variants affecting type 2 diabetes susceptibility: A meta-analysis. Gene 530: 301-308, 2013.

73. Matthaiou CM, Goutzourelas N, Stagos D, Sarafoglou E, Jamurtas A, Koulocheri SD, Haroutounian SA, Tsatsakis AM and Kouretas D: Pomegranate juice consumption increases GSH levels and reduces lipid and protein oxidation in human blood. Food Chem Toxicol 73: 1-6, 2014.

74. Samaras A, Tsarouhas K, Paschalidis E, Giamouzis G, Triposkiadis F, Tsitsimpikou C, Becker AT, Goutzourelas N and Kouretas D: Effect of a special carbohydrate-protein bar and tomato juice supplementation on oxidative stress markers and vascular endothelial dynamics in ultra-marathon runners. Food Chem Toxicol 69: 231-236, 2014.

This work is licensed under a Creative Commons Attribution-NonCommercial-NoDerivatives 4.0 International (CC BY-NC-ND 4.0) License. 